\title{
Comparative Evaluation of Canal-shaping Ability between WaveOne and ProTaper Rotary Using Cone-beam Computed Tomography: A Systematic Review
}

\author{
Reetubrita Bhol ${ }^{1}$, Soumya Shetty ${ }^{2}$, Rajesh Shetty ${ }^{3}$, Amita D Patil ${ }^{4}$, Eshani H Shah ${ }^{5}$
}

\begin{abstract}
Aim: To perform a systematic review comparing the canal-shaping ability of WaveOne and ProTaper rotary using cone-beam computed tomography (CBCT) and to evaluate the file that provides better performance clinically.

Materials and methods: The eligibility criteria selected for the study was based on the population intervention comparison outcome(s) study (PICOS). Using different search strategies from the keywords and their combinations, English language articles only between January 1, 2009, and October 31, 2019, from electronic biomedical journal databases were obtained. In vitro studies comparing the canal-shaping ability of ProTaper and WaveOne file systems using the CBCT method were included. Total 137 articles were reviewed out of which 61 articles were excluded during title screening as they did not meet the motive of our study. Total 76 articles were screened for duplicates and 63 articles were excluded. A total of 13 articles were selected for reviewing abstract and full text. Total 13 relevant articles were selected for final synthesis. The pilot Microsoft Excel sheet was filled with the relevant data that matched the study.

Review results: Total 13 relevant articles were selected for final review. The file systems were compared based on two main parameters such as the apical transportation caused and the ability of the file to remain centered within the canal. We found significant differences in these two parameters when the WaveOne reciprocating file system was compared with the ProTaper rotary file system. A definite conclusion could be drawn that the WaveOne reciprocating file system was better in shaping the canal.

Conclusion: Based on the results, the canal-shaping ability of the WaveOne reciprocating file system was better than the ProTaper rotary file system. Clinical significance: Clinically, the canal-shaping ability determines the performance of a particular file system and CBCT is the most effective 3-D mode to determine the centering ratio and apical transportation caused. Thus, further comparative studies between these two file systems using CBCT with larger sample size and with elaborate search strategies are required for better result.

Keywords: Apical transportation, Canal-shaping ability, Centering ability, Cone-beam computed tomography, ProTaper, Root canal preparation, WaveOne.

World Journal of Dentistry (2020): 10.5005/jp-journals-10015-1769
\end{abstract}

\section{INTRODUCTION}

Root canal preparation is an important step of root canal treatment. Preserving the actual anatomy of the canal is very important. ${ }^{1}$ Canal shaping largely decides the results of the following stages of treatment such as irrigation and obturation of the canal. ${ }^{2}$ Transportation is caused when endodontic instrument tends to straighten the root canal during the biomechanical preparation. ${ }^{3,4}$ The overpreparation of the root canal leads to loss of dentin, thus making the tooth prone to fracture. ${ }^{5}$

Conventional stainless steel hand instruments were not able to meet these goals. ${ }^{6,7}$

Thus, the nickel-titanium (NiTi) alloys were introduced. ${ }^{8,9}$ The super elastic property of the alloy helps the files to remain well centered and shapes the canals with less transportation.

Thus, improvement in the ability of canal shaping with less procedural damage was made. In the last few years, changes in the structure and manufacturing process of the instruments have been introduced to increase their reliability, effectiveness, and safety. ${ }^{10,11}$

The NiTi rotary instrument such as ProTaper (Dentsply Maillefer, Ballaigues, Switzerland) has an improved cross-sectional design that efficiently removes dentin, reducing the torsional stresses. But it leads to more amount of canal transportation when used aggressively. ${ }^{12}$ \begin{tabular}{l}
\hline${ }^{1-5}$ Department of Conservative Dentistry and Endodontics, Dr. DY Patil \\
Dental College and Hospital, Dr. DY Patil Vidyapeeth, Pimpri, Pune, \\
Maharashtra, India
\end{tabular}

Corresponding Author: Reetubrita Bhol, Department of Conservative Dentistry and Endodontics, Dr. DY Patil Dental College and Hospital, Dr. DY Patil Vidyapeeth, Pimpri, Pune, Maharashtra, India, Phone: +91 9890575968, e-mail: reetubritabhol1994@gmail.com

How to cite this article: Bhol R, Shetty S, Shetty R, et al. Comparative Evaluation of Canal-shaping Ability between WaveOne and ProTaper Rotary Using Cone-beam Computed Tomography: A Systematic Review. World J Dent 2020;11(5):413-420.

Source of support: Nil

Conflict of interest: None

Recently, WaveOne (Dentsply Maillefer, Ballaigues, Switzerland), a reciprocating file system, has been introduced. WaveOne files are featured from the M-wire, which is created by thermal treatment. ${ }^{13}$ This increases the file tendency to bend, and cyclic fatigue induced in the file is reduced. ${ }^{14}$ The system uses reciprocating motion. ${ }^{15}$ The reciprocating nature of the file system prevents the file to get engaged with the root canal call during preparation, thus reducing the chances of fracture of instruments. ${ }^{16}$

(0) The Author(s). 2020 Open Access This article is distributed under the terms of the Creative Commons Attribution 4.0 International License (https://creativecommons. org/licenses/by-nc/4.0/), which permits unrestricted use, distribution, and non-commercial reproduction in any medium, provided you give appropriate credit to the original author(s) and the source, provide a link to the Creative Commons license, and indicate if changes were made. The Creative Commons Public Domain Dedication waiver (http://creativecommons.org/publicdomain/zero/1.0/) applies to the data made available in this article, unless otherwise stated. 
The centering ability is characterized by the structure of the instrument and the root canal outline. The instrument undergoes less resistance and is more centered in straight root canals.

Cone-beam computed tomography (CBCT) has been widely used to produce three-dimensional details about the hard and soft tissues of the head and neck region with an effectively less amount of radiation dose when compared with conventional computed tomography. Advantages include less exposure time, high resolution with accurate image sharpness, and less distortion of images. ${ }^{17}$

The canal-shaping ability is an important factor governing the efficiency of any file system. And, nowadays, due to various advantages, CBCT is the best means of studying the detailed features on a particular file system.

Thus, this systematic review aimed to compare the canalshaping ability of WaveOne and ProTaper rotary using CBCT and to evaluate the file that provides better performance clinically.

\section{Materials and Methods}

The study was conducted at Dr. DY Patil Dental College and Hospital, Pimpri, Pune. Formulation of a research question was done according to the population intervention comparison outcome(s) study (PICOS) format aiming at the apical transportation and centering ability of a particular file system.

"Which file system has the better canal-shaping ability?"

The eligibility criteria for the study were selected and were based on the PICOS. The PICOS guidelines that were selected were: $P$ as Participants, freshly extracted human teeth were considered. I as the Intervention, WaveOne reciprocating file system was considered. C as comparison was considered as the ProTaper rotary file system. $\mathrm{O}$ as the outcome where canal-shaping ability of the file systems was assessed. $\mathrm{S}$ as the study designs, in vitro studies were included.

For the electronic search strategy, the following terms were used as keywords in several combinations: apical transportation, canal-shaping ability, centering ability, CBCT, ProTaper, root canal preparation, and WaveOne. These combinations were used to search the available articles from different electronic biomedical journal databases such as PubMed, Google Scholar, and ResearchGate.

Full-text English language articles only between January 1, 2009, and October 31, 2019, were selected. Only in vitro studies comparing the canal-shaping ability of WaveOne and ProTaper file systems using CBCT were included. Reviews, case reports, abstracts, letters to editors, editorials and animal studies, and in vivo studies were excluded.

Total 137 articles were identified through the database searching. After thorough reading of titles, 61 articles were excluded based on the parameters and inclusion criteria of our study. After searching for duplicates, 63 articles were excluded. These remaining 13 articles were further screened for abstract reading and no articles was excluded. Full texts for these 13 articles were obtained and were assessed for eligibility. All these 13 articles qualified and were selected. Number of investigators involved in this article reviewing process were five.

A pilot Microsoft Excel sheet was filled with only relevant data that matched the study.

The headings specifying author details, study design, sample size, and methodology were mentioned under which the data were tabulated. Population/products include freshly extracted human teeth. Intervention is the WaveOne reciprocating file system and comparison was done with the ProTaper rotary file system. The canal-shaping ability of both the file systems were mentioned according to the articles. Mean values and standard deviation (SD) were also mentioned for all the groups. Conclusion was mentioned according to the study's protocol.

\section{Results}

Flowchart 1 shows the Preferred Reporting Items for Systematic reviews and Meta-Analyses (PRISMA)-based articles selection process.

Total 13 relevant articles were selected for final review.

Studies differed in their sample number per group. Maximum studies ( 8 out of 13) had 10 and 20 samples per group. Four studies

Flowchart 1: PRISMA flowchart of search results and study selection

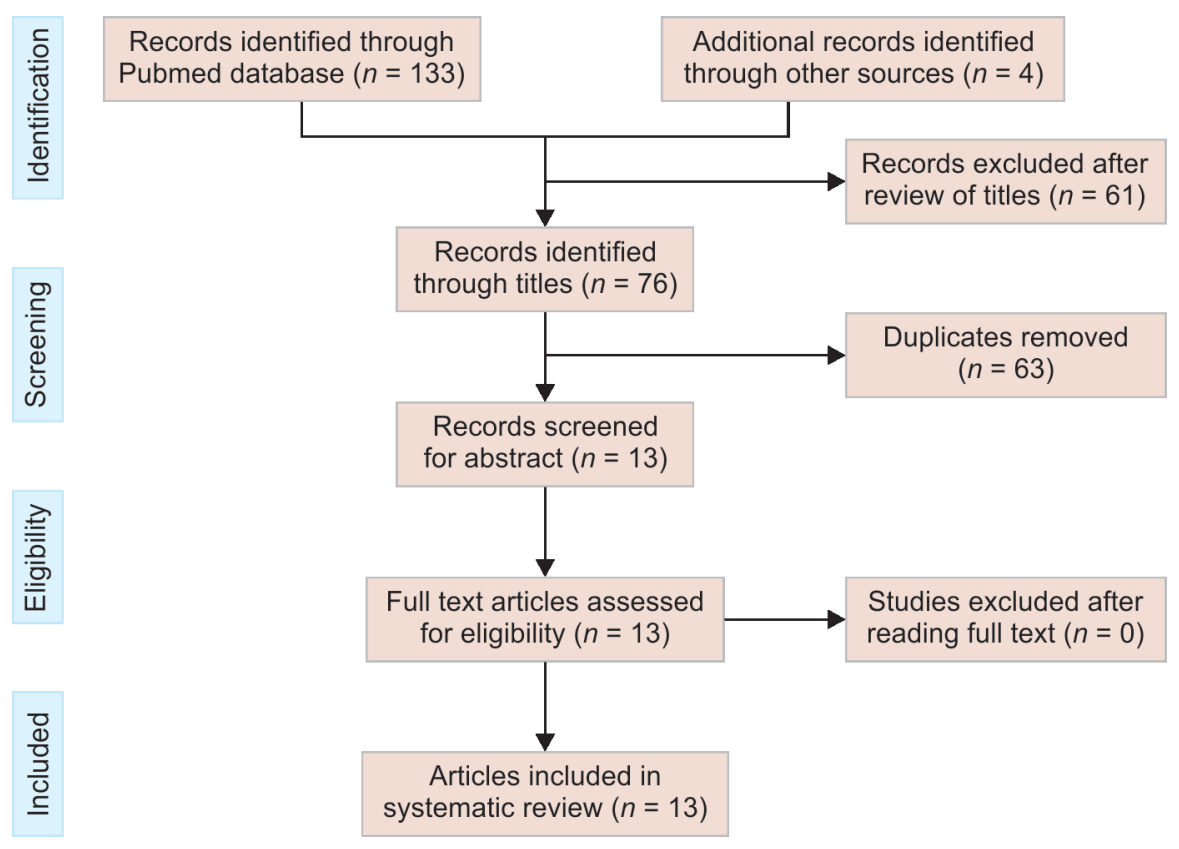


had 10 samples per group. ${ }^{18-21}$ While other four studies had 20 samples per group. ${ }^{22-25}$

The analysis of the studies according to the region showed that India had the highest number of studies being selected. 19,20,22,23,26-28 Followed by Brazil having three studies. ${ }^{25,29,30}$ And one each from Saudi Arabia, ${ }^{18}$ Thailand, ${ }^{21}$ and Turkey. ${ }^{24}$

The WaveOne reciprocating file system and the ProTaper rotary file system were compared based on two main parameters such as the apical transportation of the canal caused and the ability of the file to remain centered in the canal. Table 1 comprises the details of the studies considered for review.

A definite conclusion could be drawn that the WaveOne reciprocating file system was better in shaping the canal as 8 out of 13 studies supported it. ${ }^{18-23,26,29}$ The ProTaper rotary file system was supported by two studies. ${ }^{27,30}$ No significant differences between the file systems were shown by three studies. ${ }^{24,25,28}$

One of the study did not show any statistically significant differences in apical transportation values when the two file systems were compared. ${ }^{29}$

While comparing the centering ability values of both the files, no statistically significant difference was observed in one of the studies. $^{23}$

\section{Discussion}

Biomechanical preparation of the canal system is regarded as the main part of root canal treatment. Disruption of the original canal anatomy leads to overinstrumentation, which causes removal of dentin wall excessively, making the canal outline straight with formation of ledges. ${ }^{31}$ Thus, the significance of maintaining the original root canal space outline after biomechanical preparation is of utmost importance, which has been stressed upon in different studies. ${ }^{32}$ Nonaggressive nature of NiTi instruments along with their flexibility and imparting less amount of force are their advantages. ${ }^{33}$ Till date, different NiTi files systems have been introduced and studied in dentistry. The WaveOne file system has been introduced recently. Initially, the rotary file system was used. The ProTaper file system was regarded as a standard rotary file. Many studies have been performed based on its clinical performance. The flexibility and efficiency of cutting are the features of rotary ProTaper files, which prevent overinstrumentation by creating a conical shape, thus have less risk of transportation of the canal apically. ${ }^{34}$ The WaveOne system is a single-file reciprocating system used to prepare the entire canal space in a single step. It is based on a reverse "balanced force" action. The M-wire technology is used to manufacture it to enhance strength and cyclic fatigue resistance. ${ }^{35}$ The WaveOne file system lacks much of the supportive literature related to its canal-shaping performance. Assessment of data worldwide collectively to assess factors governing its efficacy is needed. Thus, in this present study, newly introduced, the WaveOne reciprocating file system is compared with the ProTaper rotary file system to assess whether the reciprocating motion of the file is better in shaping the canal than the rotary motion.

Cone-beam computed tomography is a commonly used technique having advantages, which include preservation of the sample. It helps in capturing different images, specifying appropriate features of the canal space prior, during, and after the root canal preparation. ${ }^{36-38}$ Thus, CBCT is regarded as an accurate procedure in determination of the efficiency of techniques and was considered as an evaluation tool in this study.

The relevant articles were reviewed on the basis of canalshaping ability including the apical transportation caused after biomechanical preparation and centering ability of the particularly two file systems: ProTaper rotary file system and WaveOne reciprocating file system.

On comparing one of the parameter of the study, apical transportation,

Mamede-Neto et al. found no statistically significant difference in-between the two file systems. ${ }^{29}$ The reason behind this may be that the amount of preparation needed and the different levels along the root length considered for measurement were not standardized. ${ }^{29}$ Apical transportation was not considered as a parameter by Dhingra et al. and Puri et al. in their studies to describe the canal-shaping ability of the files. ${ }^{27,28}$ While comparing the centering ability values of both the file systems, Jain et al. showed no statistically significant difference in their study. ${ }^{23}$ Possible reason for this finding is that the noncutting tips of all the instruments act upon less amount of apical pressure as a guide for easy entry into the canal. ${ }^{28}$

Based on the results in this present study, it can be concluded that the WaveOne reciprocating file system has better ability to shape the canal than the ProTaper rotary file system. ${ }^{18-23,26,29}$ The rigidity of the ProTaper system with stiff tip and increasing taper of the instrument reduces the remaining dentin thickness creating a straight canal. ${ }^{23}$ The flexibility of the instrument is greatly reduced by the convex structure of the core mass. ${ }^{26}$ The reciprocating motion of the WaveOne file decreases the chance of engaging in the canal by reversing the direction of rotation continually. The contraclockwise motion helps the apical penetration of the file, whereas the clockwise action prevents the file from engaging in the root wall. ${ }^{22}$ It has the presence of two different cross-sections in the active portion with variable pitch and helical angle, which decreases the diameter of the core, thus increasing the flexibility of the file. ${ }^{26}$ According to studies done by Dhingra et al. and MamedeNeto et al., ProTaper rotary files prepared the canals better. ${ }^{27,30}$ The design of the tip and the brushing strokes favored the canal-shaping ability of ProTaper. The decrease in the torsional stresses increased the resistance to fracture within the canal. ${ }^{27}$ ProTaper Gold differs from the other files from the ProTaper family as it is specialized with heat treatment, which reduced the apical transportation caused and kept the file centered in the canal. Studies done by Capar et al., Hoppe et al., and Puri et al. after comparing both the files showed neutral results with no statistically significant differences. ${ }^{24,25,28}$ Though no significant differences are found between the two files, certain amount of deviation is observed with WaveOne. Coronal preflaring and a glide path would reduce the stresses created and prevent the file from binding in the canal. ${ }^{25}$ Noncutting tips of the files only act as a guide for penetration into the canal with less amount of applied pressure. ${ }^{28}$ Differences in the methodology, apical enlargement caused, and criteria for evaluation justified the differences in results found among the studies. ${ }^{29}$ The efficiency of a single file system depends on the differences in their reciprocating angles and movement. ${ }^{18}$ Jain et al. and Mamede-Neto et al. showed that original anatomy of the canal was well preserved by the WaveOne single reciprocating file. ${ }^{23,29}$ Reciprocating files take less time to prepare the root canal efficiently compared to rotary files. ${ }^{21,25}$ Various single-file systems are introduced lately in the market. Creation of a proper glide path reduces the chances of friction of the file against the root canal wall, thus maintaining the original anatomy of the root canal. ${ }^{39,40}$ Studies conducted using single-file systems stated that the smaller-sized taper and flexibility of the instruments defines the root canal accurately. ${ }^{41}$ The single-file system with reciprocating motioncaused less amount 


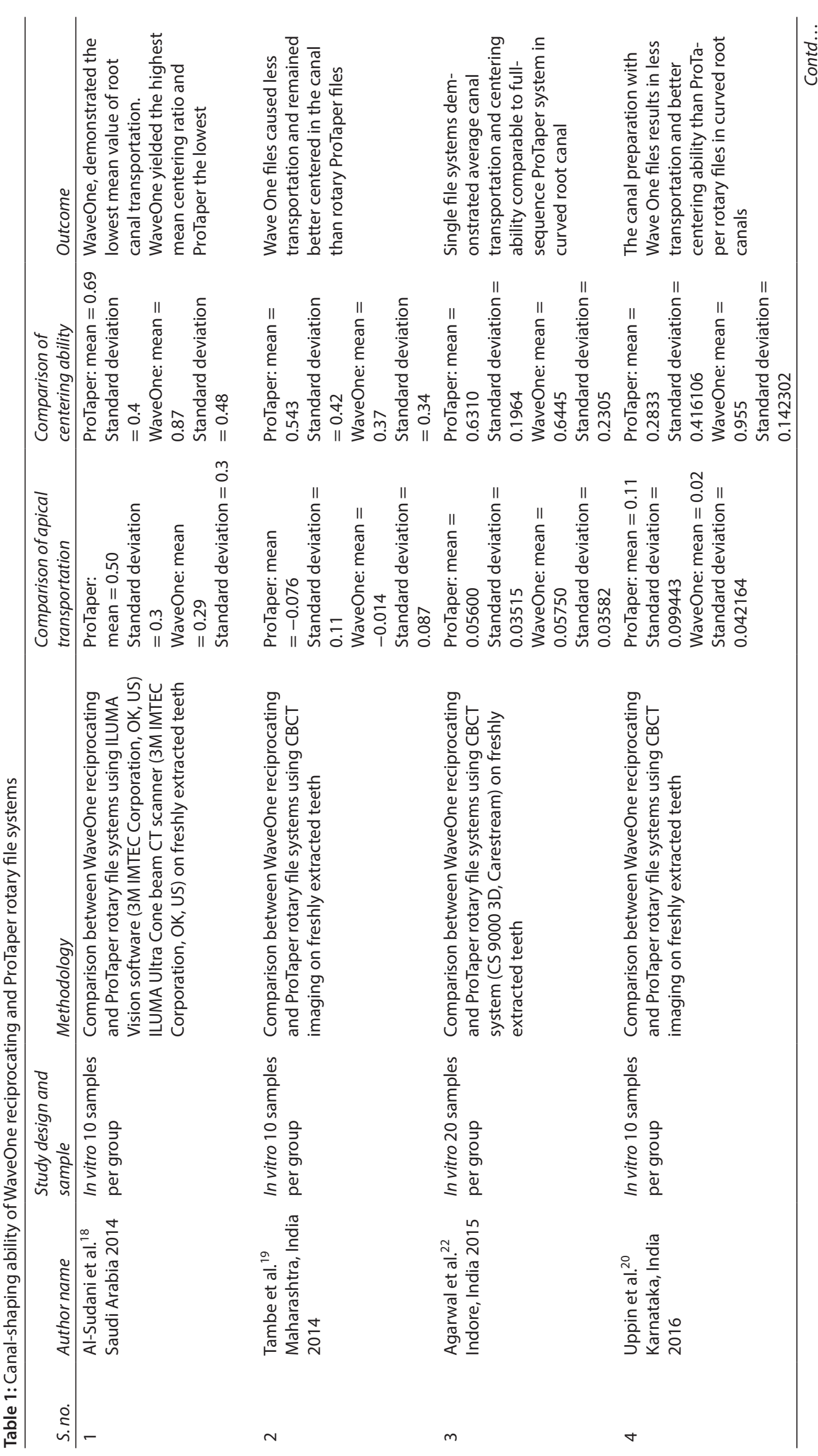




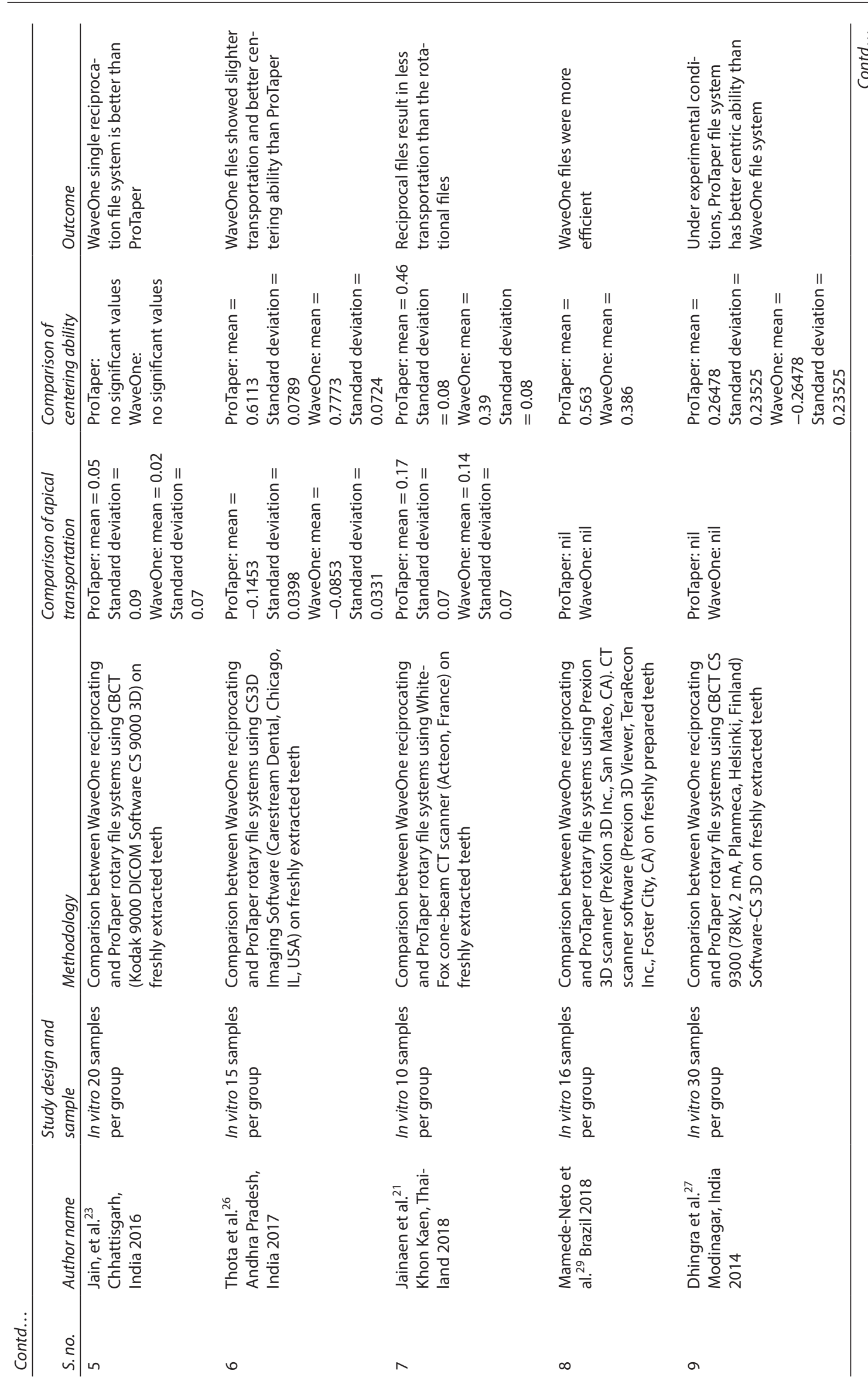




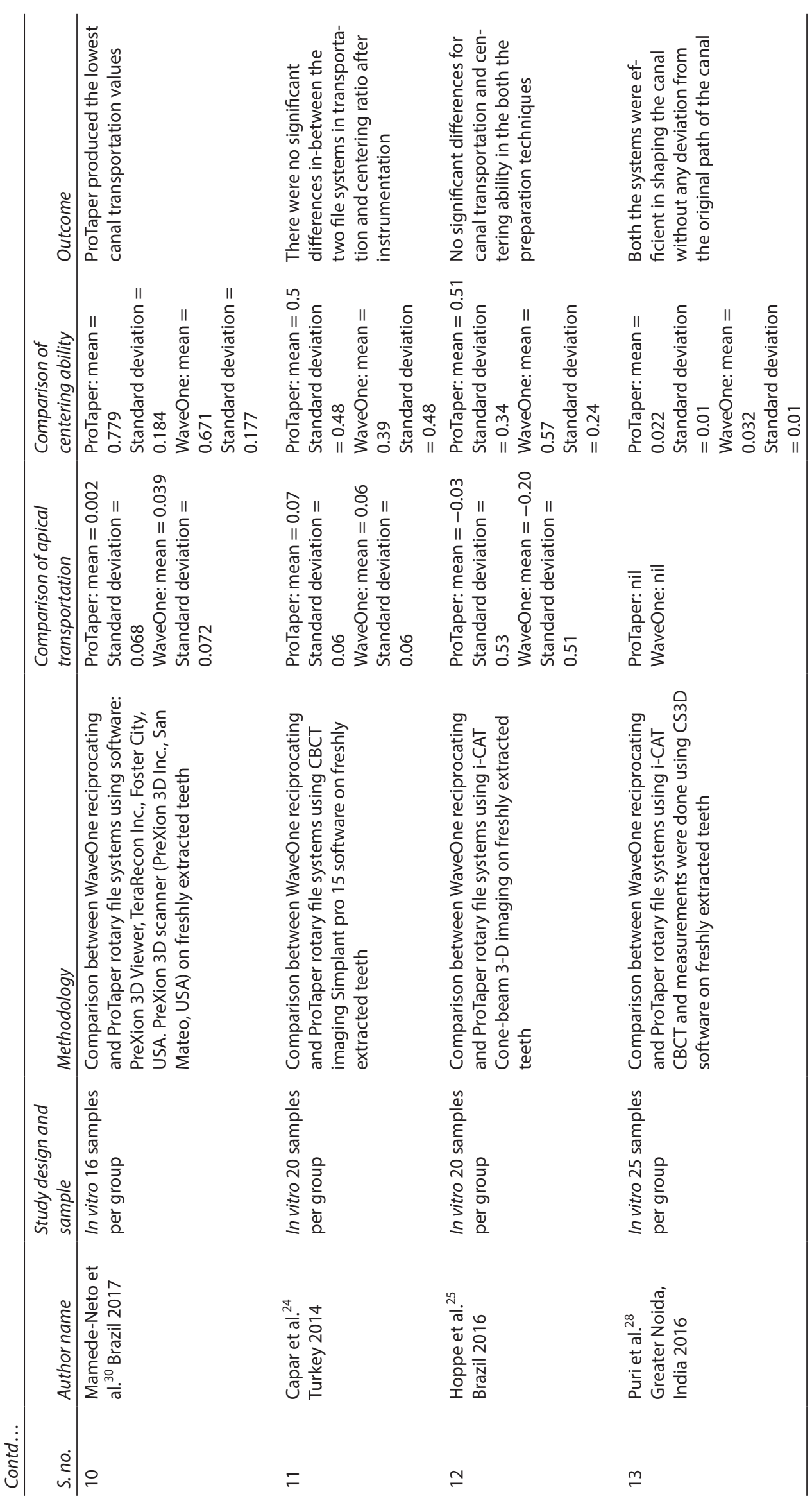


of transportation apically and remained well centered in the root canal system. ${ }^{42}$

The limitation of this study was that research and publications related to this concerned topic are limited leading to restrictions in our systematic review. There were limited full-text articles to analyze and because of less access to search forums, this study did not give concrete conclusions due to inadequate search of the literature. Studies with larger sample size and with elaborate search strategies are required for better result.

\section{Conclusion}

Keeping in mind the limitations of this study, it can be concluded that canal-shaping ability of WaveOne reciprocating files was better than ProTaper rotary files. Clinically, the canal-shaping ability determines the performance of a particular file system and CBCT is the most effective 3-D mode to determine the centering ratio and apical transportation caused. Thus, further comparative studies between these two file systems using CBCT are to be conducted to give a concrete idea.

\section{ACKnowledgments}

I owe my gratitude to all those people who have made this review possible.

I take this opportunity to express my heartfelt and sincere gratitude to my family Dr Anup Kumar Bhol, Mrs. Nivedita Bhol, and Mr. Deepanjan Bhol. Through good times and bad times, you have always been there for me guiding me on the right path. You gave me the support that I needed to build a dream to chase after.

It cannot be argued with that the most influential person in my postgraduate career has been my guide, advisor, and mentor Dr Soumya Shetty. From bottom of my heart, I thank her for her relentless encouragement, constant appraisal, sincere guidance, critical observation, sense of discipline, eye for perfection, knowledge, dedication, and optimism, which helped me to do the best of me to achieve my goals. I am especially grateful to her for devotion to her student's education and success.

My deepest appreciation to Dr Rajesh Shetty, Professor and Head of the Department of Conservative Dentistry and Endodontics, Dr. DY Patil Dental College and Hospital, in helping me for the completion of this review and for his guidance throughout the course of the study. I wholeheartedly thank for his critical assessment, kind appreciation, and minute analysis of the review. Words cannot express my gratitude for discipline and systemic organization in every small work that he has taught.

A deep and sincere thanks to my senior Dr Amita Patil who has shaped my thoughts and actions and encouraged me to do the best. Words cannot voice the tremendous support, mentorship, and constant encouragement she offered me throughout these years. Sincere thanks to my colleague Dr Eshani Shah for constantly being there whenever I needed any professional help. Without her it would have taken a lot more time for me to figure out many things.

\section{References}

1. Schilder H. Cleaning and shaping the root canal. Dent Clin North Am 1974;18:269-296.

2. Kandaswamy D, Venkateshbabu N, Porkodi I, et al. Canal-centering ability: an endodontic challenge. J Conserv Dent 2009;12(1):3-9. DOI: 10.4103/0972-0707.53334.

3. You SY, Kim HC, Bae KS, et al. Shaping ability of reciprocating motion in curved root canals: a comparative study with microcomputed tomography. J Endod 2011;37(9):1296-1300. DOI: 10.1016/j. joen.2011.05.021.

4. De-Deus G, Moreira EJ, Lopes HP, et al. Extended cyclic fatigue life of F2 ProTaper instruments used in reciprocating movement. Int Endod J 2010;43(12):1063-1068. DOI: 10.1111/j.1365-2591.2010.01756.x.

5. Ganesh A, Venkateshbabu N, John A, et al. A comparative assessment of fracture resistance of endodontically treated and re-treated teeth: an in vitro study. J Conserv Dent 2014;17(1):61-64. DOI: 10.4103/09720707.124146.

6. Schäfer E, Vlassis M. Comparative investigation of two rotary nickeltitanium instruments: ProTaper versus RaCe. Part 1. Shaping ability in simulated curved canals. Int Endod J 2004;37(4):229-238. DOI: 10.1111/j.0143-2885.2004.00786.x.

7. Elnaghy AM, Elsaka SE. Shaping ability of ProTaper Gold and ProTaper universal files by using cone-beam computed tomography. Indian J Dent Res 2016;27(1):37-41. DOI: 10.4103/0970-9290.179812.

8. Nagaraja S, Sreenivasa Murthy BV.CT evaluation of canal preparation using rotary and hand $\mathrm{NI}-\mathrm{Tl}$ instruments: an in vitro study. J Conserv Dent 2010;13(1):16-22. DOI: 10.4103/0972-0707.62636.

9. Gundappa M, Bansal R, Khoriya S, et al. Root canal centering ability of rotary cutting nickel titanium instruments: a meta-analysis. J Conserv Dent 2014;17(6):504-509. DOI: 10.4103/0972-0707.144567.

10. Viana AC, Chaves Craveiro de Melo M, Guiomar de Azevedo Bahia $M$, et al. Relationship between flexibility and physical, chemical, and geometric characteristics of rotary nickel-titanium instruments. Oral Surg Oral Med Oral Pathol Oral Radiol Endod 2010;110(4):527-533. DOI: 10.1016/j.tripleo.2010.05.006.

11. Tzanetakis GN, Kontakiotis EG, Maurikou DV, et al. Prevalence and management of instrument fracture in the postgraduate endodontic program at the dental school of Athens: a five-year retrospective clinical study. J Endod 2008;34(6):675-678. DOI: 10.1016/j. joen.2008.02.039.

12. Maitin N, Arunagiri $D$, Brave $D$, et al. An ex vivo comparative analysis on shaping ability of four NiTi rotary endodontic instrument using spiral computed tomography. J Conserv Dent 2013;16(3):219-223. DOI: 10.4103/0972-0707.111318.

13. Johnson E, Lloyd A, Kuttler S, et al. Comparison between a novel nickel-titanium alloy and 508 nitinol on the cyclic fatigue life of ProFile 25/.04 rotary instruments. J Endod 2008;34(11):1406-1409. DOI: 10.1016/j.joen.2008.07.029.

14. Shen Y, Cheung GS, Bian Z, et al. Comparison of defects in ProFile and ProTaper systems after clinical use. J Endod 2006;32(1):61-65. DOI: 10.1016/j.joen.2005.10.017.

15. Dhingra A, Kochar R, Banerjee S, et al. Comparative evaluation of canal curvature modifications after instrumentation with One Shape rotary and Wave One reciprocating files. J Conserv Dent 2014;17(2):138-141. DOI: 10.4103/0972-0707.128049.

16. Plotino G, Grande NM, Testarelli L, et al. Cyclic fatigue of Reciproc and WaveOne reciprocating instruments. Int Endod J 2012;45(7):614-618. DOI: 10.1111/j.1365-2591.2012.02015.x.

17. Scarfe WC, Farman AG. What is cone-beam CT and how does it work? Dent Clin North Am 2008;52(4):707-v. DOI: 10.1016/j.cden.2008.05.005.

18. Al-Sudani $\mathrm{D}$, Kaabi $\mathrm{H}, \mathrm{Al}$ Gamdi A, et al. The influence of different angles and reciprocation on the shaping ability of two nickel-titanium rotary root canal instruments. J Contemp Dent Pract 2014;15(4):451455. DOI: 10.5005/jp-journals-10024-1561.

19. Tambe VH, Nagmode PS, Abraham S, et al. Comparison of canal transportation and centering ability of rotary ProTaper, one shape system and wave one system using cone beam computed tomography: an in vitro study. J Conserv Dent 2014;17(6):561-565. DOI: 10.4103/0972-0707.144605.

20. Uppin V, Varghese VS, Pujar M, et al. Comparison of canal transportation and centering ability of ProTaper next, Hyflex CM and wave one system using cone-beam computed tomography-an in-vitro study. Dent J Adv Stud 2016;04(II):088-093. DOI: 10.1055/s0038-1672052.

21. Jainaen A, Mahakunakorn N, Arayatrakullikit U, et al. Cone-beam computed tomography evaluation of curved root canals prepared 
using reciprocal rotary files and rotational rotary files. J Conserv Dent 2018;21:32-36.

22. Agarwal RS, Agarwal J, Jain P, et al. Comparative analysis of canal centering ability of different single file systems using cone beam computed tomography - an in-vitro study. J Clin Diagn Res 2015;9(5):ZC06-ZC10. DOI: 10.7860/JCDR/2015/ 12097.5863

23. Jain $A$, Asrani $H$, Singhal AC, et al. Comparative evaluation of canal transportation, centering ability, and remaining dentin thickness between WaveOne and ProTaper rotary by using cone beam computed tomography: an in vitro study. J Conserv Dent 2016;19(5):440-444. DOI: 10.4103/0972-0707.190024.

24. Capar ID, Ertas H, Ok E, et al. Comparative study of different novel nickel-titanium rotary systems for root canal preparation in severely curved root canals. J Endod 2014;40(6):852-856. DOI: 10.1016/j. joen.2013.10.010.

25. Hoppe $C B$, Böttcher DE, Justo AM, et al. Comparison of curved root canals preparation using reciprocating, continuous and an association of motions. Scanning 2016;38(5):462-468. DOI: 10.1002/ sca.21297.

26. Thota MM, Kakollu S, Duvvuri M, et al. Comparative evaluation of canal shaping ability of three nickel titanium instrument systems using cone beam computed tomography: an in vitro study. Endodontology 2017;29(2):120-124. DOI: 10.4103/endo.endo_17_17.

27. Dhingra A, Gupta R, Singh A. Comparison of centric ability of ProTaper next, Wave One Protaper Using Cone Beam Computed Tomography. Endodontol 2014;26(2):244-251.

28. Puri P, Mishra A, Malik N. Comparative evaluation between two $\mathrm{NiTi}$ rotary files systems using CBCT. Int J Oral Health Med Res 2016;2(5):18-20.

29. Mamede-Neto I, Borges AH, Alencar AHG, et al. Multidimensional analysis of curved root canal preparation using continuous or reciprocating nickel-titanium instruments. Open Dent J 2018;12(1): 32-45. DOI: 10.2174/1874210601812010032.

30. Mamede-Neto I, Borges AH, Guedes OA, et al. Root canal transportation and centering ability of nickel-titanium rotary instruments in mandibular premolars assessed using cone-beam computed tomography. Open Dent J 2017;11(1):71-78. DOI: $10.2174 / 1874210601711010071$.
31. Gandhi A, Gandhi T. Comparison of canal transportation and centering ability of hand ProTaper files and rotary ProTaper files by using micro computed tomography. RSBO 2011;8(4):375-380.

32. Ingle Jl, Bakland LK. Endodontic mishaps: their detection, correction and prevention. ch. 145th ed. Endodontics. Elsevier BC; 2002. p. 775.

33. Dhingra A, Srivastava $P, C$ hadda $D$, et al. Simplify your endodontics with single file systems- case reports. J Dent and Med Sci 2013;6(6):44-51.

34. One shape $R$ for endodontic instrumentation-Inside Dentistrydental AEGIS.com. 2013 Feb; 9(2).

35. Hartmann MS, Barletta FB, Camargo-Fontanella VR, et al. Canal transportation after root canal instrumentation: a comparative study with computed tomography. J Endod 2007;33(8):962-965. DOI: 10.1016/j.joen.2007.03.019.

36. Gambill JM, Alder M, del Rio CE. Comparison of nickel-titanium and stainless steel hand-file instrumentation using computed tomography. J Endod 1996;22(7):369-375. DOI: 10.1016/S00992399(96)80221-4.

37. Versiani MA, Pascon EA, de Sousa $C J$, et al. Influence of shaft design on the shaping ability of 3 nickel-titanium rotary systems by means of spiral computerized tomography. Oral Surg Oral Med Oral Pathol Oral Radiol Endod 2008;105(6):807-813. DOI: 10.1016/j.tripleo.2007.12.012.

38. Howerton WB. Jr, Mora MA. Advancements in digital imaging: what is new and on the horizon? J Am Dent Assoc 2008;139:20-24S. DOI: 10.14219/jada.archive.2008.0354.

39. Berutti $E$, Negro AR, Lendini $M$, et al. Influence of manual preflaring and torque on the failure rate of ProTaper rotary instruments. J Endod 2004;30(4):228-230. DOI: 10.1097/00004770-200404000-00011.

40. Patino P, Biedma B, Liebana C, et al. The influence of a manual glide path on the separation rate of NiTi rotary instruments. J Endod 2005;31(2):114-116. DOI: 10.1097/01.don.0000136209.28647.13.

41. D'Amario $M$, Baldi $M$, Petricca $R$, et al. Evaluation of a new nickeltitanium system to create the glide path in root canal preparation of curved canals. J Endod 2013;39(12):1581-1584. DOI: 10.1016/ j.joen.2013.06.037.

42. de Carvalho GM, Sponchiado Junior EC, Garrido AD, et al. Apical transportation, centering ability, and cleaning effectiveness of reciprocating single-file system associated with different glide path techniques. J Endod 2015;41(12):2045-2049. DOI: 10.1016/j. joen.2015.09.005. 